\title{
APPROACH WITH ULTRASOUND-GUIDED PIRIFORMIS BLOCKS FOR PAIN RELIEF AND CONFIRMATION OF THE CLINICAL DIAGNOSIS OF DEEP GLUTEAL PAIN
}

\author{
MONRES JOSÉ GOMES', JOSÉ VICTOR LISBOA CARDOSO GOMES², HEBE SOLEDAD SIMÕES GOMES DE MOURA³, \\ DOMINGOS RODRIGUES DE MOURA JÚNIOR ${ }^{3}$, GILLIATT SAEKI DE SOUZA ${ }^{4}$, MÁRCIO DE OLIVEIRA GOMES FILHO ${ }^{5}$
}

\begin{abstract}
OBJECTIVE: The objective of this study was to demonstrate the clinical efficacy in immediate pain improvement after the ultrasound-guided puncture procedure, followed by infiltration and administration of lidocaine and betamethasone in the piriformis muscle belly.

MATERIALS AND METHODS: This retrospective and comparative study used ultrasound equipment for the punctures together with a medical tuning fork and a power Doppler. Data analysis of the last 500 cases of echo-guided procedures was performed in a reference clinic in the city of Goiânia-GO. Among these cases, ultrasound reports that contained data related to deep gluteal pain (piriformis syndrome) were selected. The following information was analyzed: age, sex, laterality and confirmation of pain improvement using the visual analog scale (VAS). All patients underwent piriformis block with ultrasound-guided puncture, followed by infiltration and administration of 2\% lidocaine, without vasoconstrictor, $6 \mathrm{ml}$ and betamethasone dipropionate $(5 \mathrm{mg} / \mathrm{mL})+$ betamethasone disodium phosphate $(2 \mathrm{mg} / \mathrm{mL})$.

RESULTS: Of the 500 procedures, 53 were related to deep gluteal pain (Piriformis Syndrome). The average age of the patients was 58 years old, being the youngest patient 21 years old and the oldest 84 years old. As for sex, there were 11 male patients, which corresponds to $21 \%$ of the cases and 42 females, which corresponds to $79 \%$ of the cases. As for laterality, the left side was the one that appeared most frequently, with 70\%, which is equivalent to 37 patients. The right side affected only 14 patients, corresponding to $26 \%$ of the cases. In addition, in two patients the involvement was bilateral, which is equivalent to $4 \%$ of cases.

CONCLUSION: The echo-guided block in the piriformis muscle belly proved to be effective for diagnostic confirmation and treatment of pain relief in deep gluteal pain syndrome, with 100\% of cases showing pain relief between 0 and 3 in the VAS (Visual Analog Scale) of 0 to 10. With the female sex being the most frequent, with an average age from both sexes of 58 years and prevalence of $70 \%$ of cases on the left side.
\end{abstract}

KEYWORDS: PIRIFORMIS SYNDROME, DEEP GLUTEAL PAIN, ULTRASONOGRAPHY.

\section{INTRODUCTION}

Deep gluteal pain syndrome (DGS) is classified among the most common and underdiagnosed pains in medicine, making it a challenge for modern orthopedics, both in diagnosis and in its treatment. The origin of DGS may be in the anatomical structures of the gluteal region, particularly in the deep gluteal space, or even in the lumbosacral spine, sacroiliac joints and hips.

In the management of this syndrome, ultrasound guidance (US) has gained importance in the last decade and has been a useful tool in propedeutics, as well as serving as a guide for punctures for test blocks, blocks with hydrodissection and other procedures in the approaches to DGS, allowing visualization of the external rotator muscle group in the deep gluteal space in a specified way and avoiding complications such as inadvertent puncture of vessels or nervous structures.

The piriformis muscle was described in 1928 by Yeoman as an etiological factor in atypical sciatica due to its anatomical variations ${ }^{1}$. Since then, DGS has been a clinical condition popularly related to the name of piriformis syndrome (PS).

The piriformis syndrome has only $6 \%$ of incidence in the general population, being more common in females than in males and increases between the fourth and fifth decade of life, according to the literature.

The clinical diagnosis is given by anamnesis and physical examination, with resistance abduction maneuvers and external rotation of the thigh (Pace test). There is also the Friberg test, which consists of abduction and passive and forced internal rotation of the affected lower limb. In these cases, patients had pain in the deep gluteal space region.

The ultrasound method allows anatomical visualization

\footnotetext{
1. Clínica Fisiogyn

2. Pontifícia Universidade Católica de Goiás

3. Faculdade Morgana Potrich

4. Ortotrauma Samaritano

5. Universidade Federal de Goiás
}

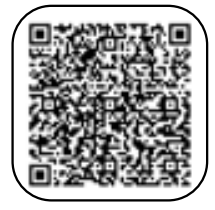

MAILING ADDRESS

MONRES JOSE GOMES

Rua 94 - 408 Setor Sul CEP 74080-100

Email: drmonroes@gmail.com 
of the piriformis muscle and its relationship with the sciatic nerve. Ultrasound-guided anesthetic piriform blockade can be performed effectively and reproducibly, with careful attention to the details of the procedure, it can be performed with minimal morbidity for the patient, and it can be performed in the office in a minimally invasive and very safe way for the patient. It can offer the opportunity for a real-time assessment of the pain relief response, using the visual analogue scale (VAS).

The objective of this study was to demonstrate the clinical efficacy in immediate pain improvement after the ultrasound-guided puncture procedure, followed by infiltration and administration of lidocaine and betamethasone in the piriformis muscle belly.

\section{METHODOLOGY}

A Samsung ultrasonography equipment, model HS 50, with multifrequency linear and convex probes was used. A $22 \mathrm{G} \times 3-1 / 2$ spinal needle was used for the punctures. In all cases, a $128 \mathrm{~Hz}$ tuning fork was used as an aid in the diagnosis and location of trigger points, together with the use of power Doppler set at $500 \mathrm{~Hz}$ - figure 1 .

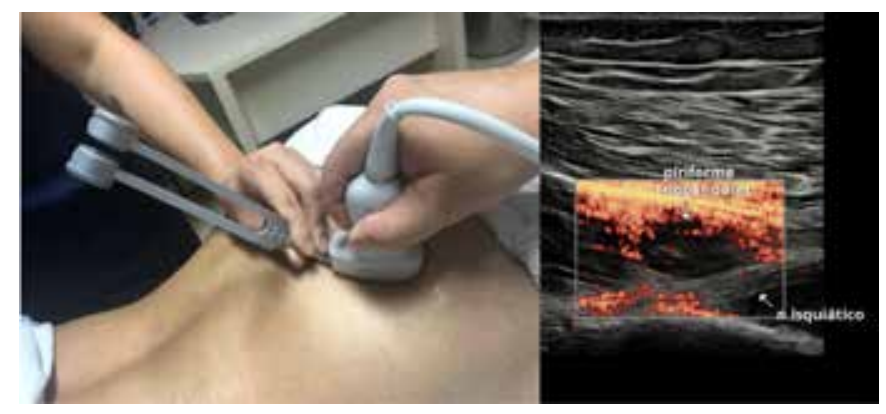

Figure 1: Intramuscular piriform trigger diagnosis using power Doppler using a $128 \mathrm{~Hz}$ tuning fork stimulus. Note that in the Trigger Point zone, the speed of sound propagates differently, remaining different from the neighboring tissue.

This retrospective and comparative study of medical record data maintained patient privacy and data confidentiality throughout the research process. This study did not have direct contact with the study group, and all patient identifiers were discarded from the data set at the time of initial collection, thus obtaining the waiver of informed consent.

Data analysis of the last 500 cases of ultrasound-guided procedures was carried out in a reference clinic in the city of Goiânia-GO. And from these, the cases whose ultrasound examination reports contained data related to deep gluteal pain (piriformis syndrome) were selected. The following information was analyzed: age, sex, laterality and confirmation of pain improvement by the visual analogue scale (VAS). After data collection and computation via Epi Info ${ }^{\mathrm{TM}}$ app | CDC, the statistical information was obtained and tabulated using the Microsoft Excel program.
All patients underwent piriform blockade with ultrasound-guided puncture, followed by infiltration and administration of $2 \%$ lidocaine without $6 \mathrm{ml}$ vasoconstrictor and betamethasone dipropionate $(5 \mathrm{mg} / \mathrm{ml})+$ betamethasone disodium phosphate $(2 \mathrm{mg} / \mathrm{ml})$ - figure 2

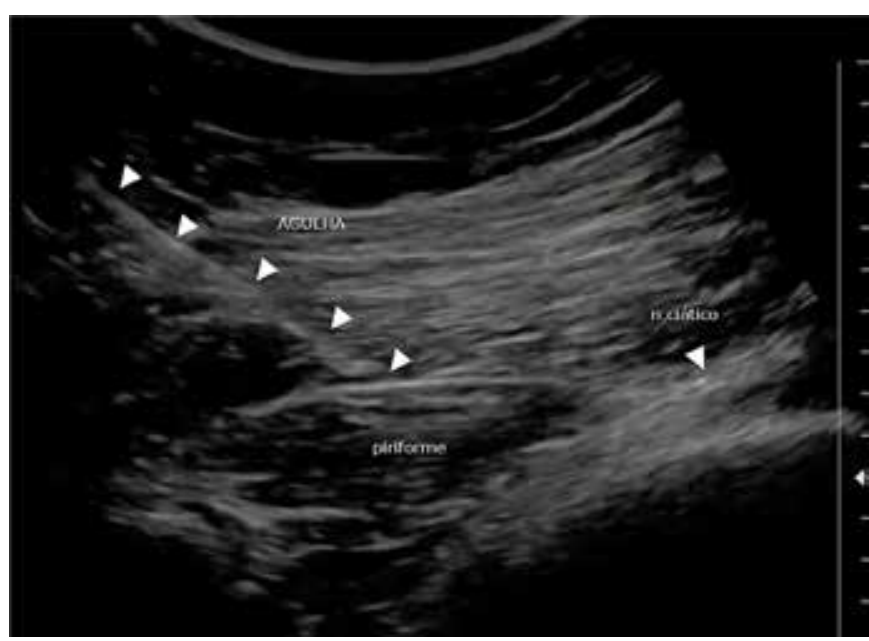

Figure 2: Ultrasound-guided piriform blockade.

\section{RESULTS}

The last 500 cases of ultrasound-guided procedures performed at the reference clinic for musculoskeletal ultrasound in Goiânia-GO, which provided the data for this research, were the basis of this work. Of these procedures, 53 $(10.6 \%)$ were from patients whose ultrasonographic exams contained data on deep gluteal pain (piriformis syndrome). Those patients underwent ultrasound-guided puncture for piriformis blockade and administration of lidocaine and betamethasone.

The mean age of patients was 58 years, with the youngest patient being 21 years old and the oldest being 84 years old. As for gender, there were 11 male patients, which corresponds to $21 \%$ of cases and 42 females, which corresponds to $79 \%$ of cases.

As for laterality, the left side was the one that appeared most frequently, with $70 \%$, which is equivalent to $37 \mathrm{pa}-$ tients. The right side affected only 14 patients, corresponding to $26 \%$ of cases. In addition, in two patients the involvement was bilateral, equivalent to $4 \%$ of cases. The visual analogue pain scale (VAS) was applied 30 minutes after the ultrasound-guided procedure and showed that $100 \%$ of patients rated pain from 0 to 3 . Data are shown in tables 1-4 and graphs $1-3$. 


\begin{tabular}{|c|cccc}
\hline C(anos) & CC & FA & FR(\%) & FRA(\%) \\
\hline $21+30$ & 26 & 2 & 4 & 4 \\
$30+39$ & 35 & 7 & 13 & 17 \\
$39+48$ & 44 & 7 & 13 & 30 \\
$48+57$ & 53 & 17 & 32 & 62 \\
\hline $57+66$ & 62 & 3 & 6 & 68 \\
\hline $66+75$ & 71 & 6 & 11 & 79 \\
\hline 75 H84 & 80 & 11 & 21 & 100 \\
\hline TOTAL & & 53 & 100 & \\
\hline
\end{tabular}

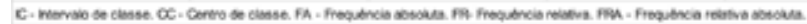

Table 1 - Age of patients treated at a clinic in Goiânia, with Piriformis Syndrome.

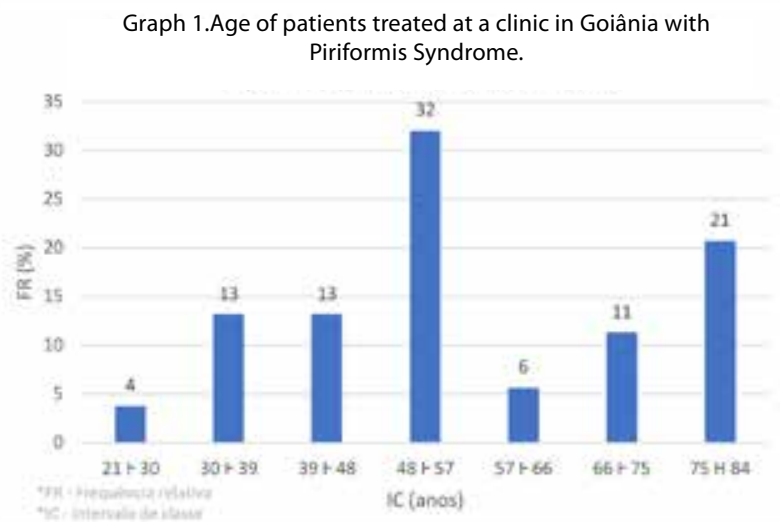

Graph 1.Age of patients treated at a clinic in Goiânia with Piriformis Syndrome.

\begin{tabular}{|c|c|c|c|}
\hline Lados & FA & FR(\%) & FRA/(\%) \\
\hline Right & 14 & 26 & 26 \\
\hline Left & 37 & 70 & 96 \\
\hline Bilateral & 2 & 4 & 100 \\
\hline TOTAL & 53 & 100 & \\
\hline
\end{tabular}

Table 2 - Side where the procedure for the treatment of Piriformis Syndrome was performed.

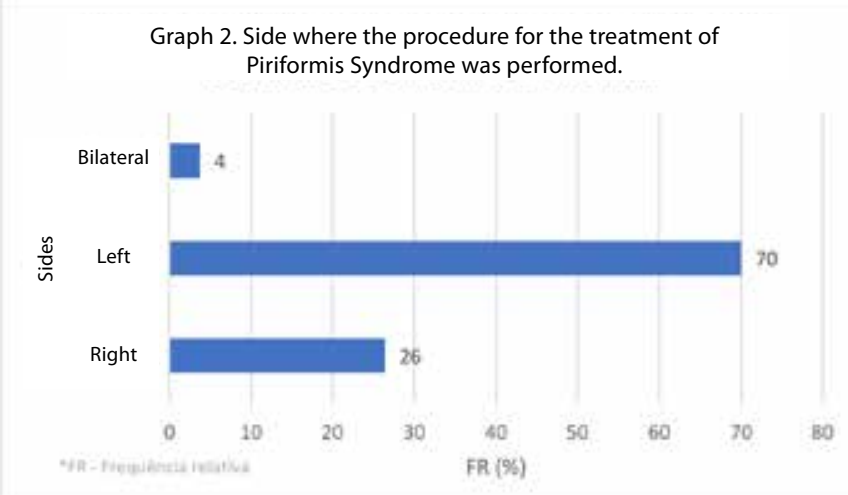

Graph 2. Side where the procedure for the treatment of Piriformis Syndrome was performed.

\begin{tabular}{cccc}
\hline Gender & FA & FR(\%) & FRA $(\%)$ \\
\hline Male & 11 & 21 & 21 \\
Female & 42 & 79 & 100 \\
\hline TOTAL & 53 & 100 &
\end{tabular}

Table 3 - Gender Distribution of patients with Piriformis Syndrome.

Graph 3. Gender Distribution of patients with Piriformis Syndrome

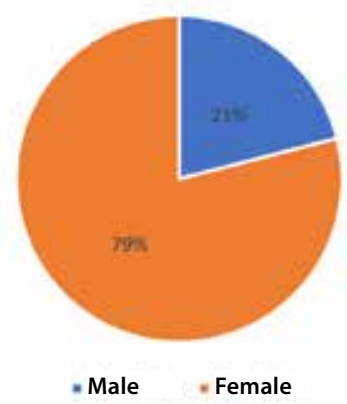

Graph 3. Gender Distribution of patients with Piriformis Syndrome

\begin{tabular}{ccccc}
\hline $\mathrm{C}(\mathrm{EVA})$ & $\mathrm{CC}$ & $\mathrm{FA}$ & $\mathrm{FR}(\mathrm{Z})$ & FRN \\
\hline $0+3$ & 2 & 53 & 100 & 100 \\
$3+6$ & 5 & 0 & 0 & \\
$6 \mathrm{H} 10$ & 8 & 0 & 0 & \\
\hline TOTA & & 53 & 100 &
\end{tabular}

Table 4 - Visual Analog Scale (VAS) of pain after the procedure in patients with Piriformis Syndrome.

Bring your camera close to the QR Code to view the videos below:

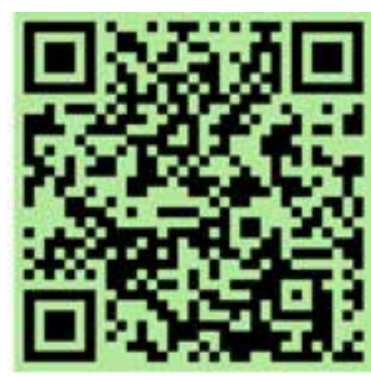

Video: Piriform Infiltration

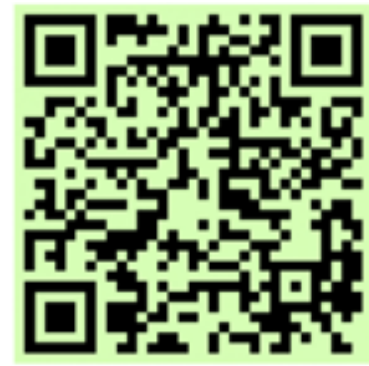

Video: Piriform with Tuning Fork 


\section{DISCUSSION}

Piriformis syndrome is a common cause of lower back, gluteal, and thigh pain, often associated with sciatic nerve symptoms. Potential etiologies include muscle injury or chronic muscle stretching associated with gait disturbances. There is a common pathological terminal pathway involving hypertrophy, spasm, contracture, inflammation and scarring of the piriformis muscle, leading to sciatic nerve shock.

Ultrasound-guided piriformis injections are frequently used in the treatment of these pain syndromes, with most of the published literature describing muscle injection.

The piriformis muscle was described in 1928 by Yeoman as an etiological factor in atypical sciatica due to its anatomical variations 1 . Since then, DGS has been a clinical condition popularly related to the name piriformis syndrome (PS).

Beaton \& Anson ${ }^{2}$ in 1937 initially described the relationship of the sciatic nerve and its subdivisions with the piriformis muscle, showing the various anatomical variants in their emergence in the deep gluteal space and concluded that the emergence distal to the belly of the piriformis was present in $84 \%$ of the patients, $12 \%$ being between and below the piriform and the other cases in other forms of anatomical variation.

Durrani \& Winnie ${ }^{3}$, performed a retrospective review of 26 patients with sciatica due to piriformis muscle syndrome. Most patients had pain in the buttocks and sciatica, and most had difficulty walking and sitting, even for short periods of time. Reproduction of sciatica on deep palpation, via the gluteal or rectal route, was diagnosed. Reproduction of sciatica occurred in $92 \%$ of patients on deep digital palpation and in $100 \%$ of patients on rectal or pelvic examination. This study emphasizes that the diagnosis of piriformis muscle syndrome is clinical.

Polesello et al ${ }^{4}$ in 2012 evaluated the anatomical variation of the piriformis muscle as a cause of deep gluteal pain and to be improved through magnetic resonance neurography.

Martin et al ${ }^{5}$ studied the endoscopic decompression of the sciatic nerve in the treatment of patients with deep gluteal pain syndrome (DGS), in 35 patients ( 28 women and seven men). Postoperative results were assessed using the modified Harris Hip Score (MHHS), the Verbal Analog Scale (VAS) score, and a questionnaire specifically related to hip sciatica. The mean age of patients was 47 years (range 20 to 66 years). Endoscopic sciatic nerve decompression has been shown to be helpful in improving function and decreasing hip pain in sciatic nerve entrapment/DGS. Mean follow-up time was 12 months (range 6 to 24 months). The mean postoperative MHHS increased to 78.0 and the VAS score decreased to ${ }^{2,4}$. About $83 \%$ of patients did not experience postoperative sciatica (inability to sit for more than 30 minutes).

Carro et $\mathrm{al}^{6}$ agree that deep gluteal pain is among the most common diagnostic and therapeutic challenges for orthopedists and radiologists. In this paper, they described the limits of the deep gluteal space, the posterior limit being the gluteus maximus muscle, the anterior limit being the poste- rior edge of the femoral neck; laterally by the linea aspera and by the lateral fusion of the layers of the gluteal medial and deep aponeurosis, reaching the tensor fascia lata muscle; the medial border by the sacrotuberous and falciform fascia; the superior limit at the inferior margin of the sciatic notch and the inferior limit at the origin of the hamstrings. They also described that the internal structures of the deep gluteal space are the superior and inferior gluteal nerves, the ischium, the sacrotuberous and sacrospinous ligament, the sciatic nerve and the external rotator muscles, being the piriformis, the superior gemelli, obturator internus, inferior gemelli and the quadratus femoris.

Demirel et $\mathrm{al}^{7}$, in 2018, in Turkey, showed by a sonoelastography study that muscle elasticity and tissue hardening increased on the sick side both in the piriformis muscle belly and in the gluteus maximus. In this work with 28 patients, 21 female and seven male, the age ranged from 24 to 62 years old, with an average of 45 years old.

Smith et al ${ }^{8}$ in 2006, proposed the description and verified the ultrasound-guided piriformis injection technique, providing very good prospects for using the US method in these procedures.

Monres JG ${ }^{9}$, in his commented Atlas of musculoskeletal ultrasonography, in 2004, already described how to assess the deep gluteal space by US and reported that piriformis syndrome occurs due to an exaggerated tension of this muscle, its hypertrophy, or also a traumatic cause, in which the lower edge of the piriformis becomes thickened by reactive fibrosis. common in men with the continued use of wallets in the back pocket of their tight pants, determining chronic piriformis pain syndrome, which can manifest as pseudo sciatica syndrome.

In 2010, Smoll NR ${ }^{10}$ reviewed the variations of the piriformis and sciatic nerves with clinical consequences and noted that the prevalence of anomalies in the emergence of sciatic nerves in the deep gluteal space in patients with piriformis syndrome is not significantly different from what is thought to be a healthy population, this indicates that this anomaly may not be as important in the pathogenesis of piriformis syndrome as previously thought.

Bevilacqua et al ${ }^{11}$ in 2016, used the injection of the piriformis muscle with local anesthetics and corticosteroids in five patients and an ultrasound-guided approach was performed and all patients had pain improvement on the VAS and only one case presented as a sciatic complication that improved spontaneously. in 10 days. They concluded that the technique is easy to be performed and has a good safety profile and good results.

Burke et al ${ }^{12}$ in 2019 described a safe and effective ultrasound-guided injection technique for the treatment of piriformis syndrome using targeted perineural sciatic hydrodissection followed by therapeutic corticosteroid injection.

Zhang et al ${ }^{13}$, in 2019, included a total of 33 patients with clinically diagnosed PS (mean age 45 years; 16 men) and 26 healthy volunteers (mean age 54 years; 15 men) 
in a cross-sectional study. They used US and RM for data comparison. Muscle thickness was measured through the cross-sectional area (CSA) in three consecutive axial slices from the point where the muscle was first visible in the greater sciatic foramen and the images were determined for each side. The images showed increased piriformis muscles on the symptomatic side in patients with PS, in addition to hypoechogenic texture and increased fascia acoustic enhancement. They concluded that US and MRI revealed similar muscle alterations in patients with PS. And these findings indicate that the US can be a reliable and convenient technique for the diagnosis of PS.

Wu et al ${ }^{14}$, in 2020 in a single-center retrospective study in which 52 patients diagnosed with piriformis syndrome and 50 healthy volunteers were enrolled to undergo ultrasound examination of the piriformis and sciatic nerve and concluded that US can help in the clinical diagnosis of piriformis syndrome.

Our work covered a group of 53 patients whose US exams contained data related to deep gluteal pain (piriformis syndrome) and were submitted to US-guided puncture for piriformis blockade and administration of lidocaine and betamethasone. The mean age of patients was 58 years, with the youngest patient being 21 years old and the oldest being 84 years old. As for gender, there were 11 male patients, which corresponds to $21 \%$ of cases and 42 females, which corresponds to $79 \%$ of cases. As for laterality, the left side was the one that appeared most frequently, with 70\%, which is equivalent to 37 patients. The right side affected only 14 patients, corresponding to $26 \%$ of cases. In addition, in two patients the involvement was bilateral, equivalent to $4 \%$ of cases. The analogue pain scale (VAS) was applied 30 minutes after the ultrasound-guided procedure and showed that $100 \%$ of patients rated pain from 0 to 3 .

\section{CONCLUSION}

Ultrasound blockade in the piriformis muscle belly proved to be effective for diagnostic confirmation and treatment of pain relief in deep gluteal pain syndrome, with $100 \%$ of cases showing pain relief between 0 and 3 on VAS from 0 to ${ }^{10}$. The most frequent sex was female, with a mean age of 58 years and a prevalence of $70 \%$ on the left side.

\section{REFERENCES}

1 Yeoman W. The relation of arthritis of the sacro-iliac joint to sciatica: with one analysis of 100 Cases. Lancet. 1928;2: 1119-23.

2 Beaton LE \& Anson BJ. The relation of the sciatic nerve and of its subdivisions to the piriformis muscle. Anat Rec. 1937;70(1):1-5.

3 Durrani Z, Winnie AP. Piriformis muscle syndrome: an underdiagnosed cause of sciatica. J Pain Symptom Manage. 1991;6(6):374379.

4 Polesello GC, Queiroz MC, Linhares JPT, Amaral DT, Ono NK. Anatomical variation of piriformis muscle as a cause of deep gluteal pain: diagnosis using MR neurography and treatment. Rev Bras Ortop. 2013;48(1): 114-117.

5 Martin HD, Shears SA, Johnson JC, Smathers AM, Palmer IJ. The endoscopic treatment of sciatic nerve entrapment deep gluteal syndrome. Arthroscopy. 2011;27(2):172-81.
6 Carro LP, Hernando MF, Cerezal L, Navarro IS, Fernandez AA, Castillo AO. Deep gluteal space problems: piriformis syndrome, ischiofemoral impingement and sciatic nerve release. Muscles, Ligaments and Tendons Journal 2016;6(3): 384-396.

7 Demirel A, Baykara M, Koca TT, Berk E. Ultrasound elastography findings in piriformis muscle syndrome. Indian I Radiol Imaging. 2018;28(4): 412-418

8 Smith J, Hurdle MF, Locketz AJ, Wisniewski SJ. Ultrasound-guided piriformis injection: technique description and verification. Arch Phys Med Rehabil. 2006;87(12): 1664-1667.

9 Gomes MJ. Atlas comentado de ultrassonografia do sistema musculoesquelético. $2^{\text {a }}$ ed. Rio de Janeiro: Revinter, Rio de Janeiro; 2011, p. 262.

10 Smoll NR. Variations of the piriformis and sciatic nerve with clinical consequence: a review. Clin Anat. 2010;23(1): 8-17.

11 Bevilacqua Alén E, Diz Villar A, Curt Nuño F, Illodo Miramontes G, Refojos Arencibia FJ, López González JM. Ultrasound-guided piriformis muscle injection. A new approach. Inyección ecoguiada del músculo piriforme. Un nuevo abordaje. Rev Esp Anestesiol Reanim. 2016;63(10): 594-598.

12 Burke CJ, Walter WR, Adler RS. targeted ultrasound-guided perineural hydrodissection of the sciatic nerve for the treatment of piriformis syndrome. Ultrasound Q. 2019;35(2):125-129.

13 Zhang W, Luo F, Sun H, Ding H. Ultrasound appears to be a reliable technique for the diagnosis of piriformis syndrome. Muscle Nerve. 2019;59(4):411-416.

14 Wu YY, Guo XY, Chen K, He FD, Quan JR. Feasibility and Reliability of an Ultrasound Examination to Diagnose Piriformis Syndrome. World Neurosurgery. 2020;134: e 1085-e1092. 